in the nickel plate in spite of filtering septa, and is probably the result of primary deposition by the current.

The use of bags over the anodes seems desirable, as they do not appreciably raise the voltage, and they keep the bath much cleaner and decrease the iron impurity in the nickel deposit by about one-half.

The surprising deficiency of the nickel deposit measured in current used, when the cathode is rotated, is interesting and will be further investigated with other metals and their compounds. This deficiency has been found to depend essentially on the speed of rotation, increasing as the speed of rotation increases. Until further investigation no attempted explanation of this fact will be advanced.

The total avoidance of smali amounts of iron in the nickel plate does not seem possible with the anodes at present used in technical work.

The problem of the pure nickel anode with an effective corroding electrolyte will be further investigated in this laboratory.

IABORATORI OF AMPIED ELLETRO-CHMMSTRY,

Worcester Folytechnic Institute.

\title{
POTASSIUM AMMONOZINCATE.
}

A RHPRESLNTATIVE OF A NEW CIASS OF COMPOLNDS.

BY ITIWARD C. FRANKIIX.

Received June 25. 1907 .

Following the program of developing the ammonia system of acids, bases and salts inaugurated in this laboratory, Mr. F. F. Fitzgerald ${ }^{1}$ has succeeded in preparing an ammonia anlogue of the potassium zincate which is geverally" assumed to be formed when metallic zinc, zinc oxide or zinc hydroxide is dissolved in an aqueons solution of potassium hydroxide. He obtained this ammono salt, to which he gave the formula, $\mathrm{Zn}(\mathrm{NHK})_{2} .2 \mathrm{NH}_{3}$, by the action of an ammonia solution of potassium anide on metallic zinc and on zinc amide in accordance with the equations:

$$
\begin{aligned}
& \mathrm{Zn}+2 \mathrm{KNH}_{2}+\mathrm{Am}_{\mathrm{m}}=\mathrm{Zn}(\mathrm{NHK})_{2} \cdot 2 \mathrm{NH}_{3}, \cdots \mathrm{H}_{2}, \\
& \mathrm{Zn}\left(\mathrm{NH}_{2}\right)_{2}+2 \mathrm{KNH}=\mathrm{Zn}(\mathrm{NHK})_{2} .2 \mathrm{NH}_{3},
\end{aligned}
$$

which are obvionsly analogous to the reactions whereby Comey and Jackson ${ }^{3}$ prepared the compounds, $\mathrm{Zn}_{3} \mathrm{O}_{6} \mathrm{Na}_{4} \mathrm{H}_{2}$. ${ }_{9} \mathrm{H}_{2} \mathrm{O}$ and $\left(\mathrm{ZnO}_{2} \mathrm{NaH}\right)_{2} \cdot 7 \mathrm{H}_{2} \mathrm{O}$, and Förster and Gïnther the componnd to which they gave the formula, $(\mathrm{OH}) \mathrm{Zn}(\mathrm{ONa}) \cdot 3 \mathrm{H}_{2} \mathrm{O}^{5}$.

Unfortunately Fitzgerald's work was brought to a sudden end by the great earthquake before entirely satisfactory evidence as to the compo-

1 This Journa1, 29,656 .

2 Abegg's Handb, anorg. Chem., 2.2, $33^{\mathrm{S}}$.

'An. Ch. J., 11, I 45 .

4 . Eilektrochem., 6, 30I.

5 This latter compound, it should be noted, is probably identical with the compound, $\left(\mathrm{Z}_{11} \mathrm{O}_{2} \mathrm{NaH}\right)_{2} \cdot 7 \mathrm{H}_{2} \mathrm{O}$, of Comey and Jackson, inasmuch as the two products differ in composition by half a molecule of water only. 
sition of his product had been procured. In view of the importance of establishing definitely the existence of a compound belonging to this group of the ammonia system, the writer has continued Mr. Fitzgerald's work and has succeeded in preparing a beatitifully crystallized compound, the analytical data for which point sharply to the formula, $\mathrm{Zn}(\mathrm{NHK})_{2}$. $2 \mathrm{NH}_{3}$, or $\mathrm{Zn}\left(\mathrm{NH}_{2}\right)_{2} .2 \mathrm{KNH}_{2}$, thus confirming the earlier results.

Preparation of Potassium Ammonozincate.-The pure compound has been prepared by the action of an excess of potassium amide in solution in liquid ammonia on pure, water-free, ammoniated zinc iodide in accordance with the equation:

$$
\mathrm{ZnI}_{2} \cdot 4 \mathrm{NH}_{3}+{ }_{4} \mathrm{KNH}_{2}=\mathrm{Zn}(\mathrm{NHK})_{2} \cdot 2 \mathrm{NH}_{3}+2 \mathrm{KI}+2 \mathrm{NH}_{3} \text {. }
$$

The manipulative details were carried out as follows, using the form of apparatus and methods of procedure previously described ${ }^{1}$ by the writer. Clean metallic potassium, together with a few milligrams of platinum black, were introduced into one leg of the apparatus, after which this leg was closed before the blow-pipe. Into the other leg was then introduced the zinc salt, which was melted in a current of ammonia gas to a perfectly clear, colorless liquid, after which the tube was sealed as usual. As soon as the conversion of the metallic potassium into potassium amide was complete, the solution of the latter was poured in excess in to the leg containing the zinc iodide. Zinc iodide is soluble as such to a limited extent only. Addition of a small quantity of potassium amide greatly increases the solubility of the zinc salt, a behavior for which the explanation is not obvious. Increasing the amount of potassium amide finally produces a permanent, flocculent precipitate which, in the presence of an excess of the precipitant, gradually, in the course of some hours, changes into a mass of dense, colorless, well formed crystals. After washing a few times the salt is obtained pure.

Method of Analysis.-For analysis the tube containing the pure salt was separated from the remainder of the apparatus and evacuated of its gaseous contents by means of a mercury pump at laboratory temperature. The tube was weighed, delivered of its contents, evacuated and weighed again, thus giving the weight of the salt which during this process has at no time been in contact with the air or other source of contamination with water. The substance in solution in dilute hydrochloric acid is divided into aliquot parts, in one of which the nitrogen is determined by distillation with potassium hydroxide and titration of the distillate after the usual volumetric method for ammonia. In another portion of the solution the zinc is precipitated by the addition, in excess, of a measured amount of a standard solution of sodium carbonate, followed by digestion on the water-bath until the ammonia is entirely removed and the precipitation of the zinc is complete. The filtrate from the zinc carbonate is

1 This Journal, 27, 830 . 
acidified with hydrochloric acid, evaporated to dryness and ignited, thus giving a mixture of known sodium chloride content.

Analytical Data. - The following analy tical results have been obtained:

Preparation I. One-fourth of $0.5962 \mathrm{~g}$. of the substance gave $0.0398 \mathrm{~g}$. nitrogen; another fourth gave $0.0586 \mathrm{~g}$. zinc oxide.

Preparation II. One-lialf of $0.6858 \mathrm{~g}$. of this preparation gave 0.0930 g. nitrogen; the other half gave $0.1367 \mathrm{~g}$. zinc oxide and $0.2446 \mathrm{~g}$. potassium chloride.

Preparation III. One-half of $0.7424 \mathrm{~g}$. of the substance gave 0.1008 g. nitrogen; one-fourth of $0.7424 \mathrm{~g}$. of the substance gave $0.0727 \mathrm{~g}$, zinc oxide and $0.1338 \mathrm{~g}$. potassium chloride.

From these results the following percentages of the respective constituents have been calculated:

\begin{tabular}{lcccc}
\multicolumn{3}{c}{ Calculated for } & \multicolumn{3}{c}{ Fond } \\
$\mathrm{N}$ & $\mathrm{Zn}(\mathrm{NHK})_{2.2 \mathrm{NH}_{3}}$ & I. & II. & III. \\
$\mathrm{Zn}$ & 27.04 & 26.7 & $27 . \mathrm{I}$ & 27.1 \\
$\mathrm{~K}$ & $3 \mathrm{I} .44$ & $3 \mathrm{I} .5$ & $3 \mathrm{I} .9$ & $3 \mathrm{I} .4$ \\
& $37.7 \mathrm{O}$ & -- & 37.5 & 37.7
\end{tabular}

It should be mentioned here that the discrepancies in the analytical data obtained by Fitzgerald were undoubtedly caused by the presence of water, very small quantities of which, acting hydrolytically nn the ammono salt, set free ammonia and form the hydroxides of zinc and potassium.

It is of further interest in this connection to uote that the writer, in his attempts to prepare, filter and wash this compound in a piece of apparatus devised for working with liquid ammonia solutions at atmospheric pressure, always obtained products which were low in ammonia and high in potassium and zinc, the results, as he believes, of his inability to exclude all traces of moisture when working with such a cold liquid as ammonia is at low pressures. The moisture probably finds its entrance past the numerous stoppers and stop-cocks used.

Properties of the Salt.-Potassium ammonozincate is but slightly soluble: in liquid ammonia, but is dissolved energetically and with the evolution of much heat in dilute aqueous acids. It is also soluble in liquid ammonia solutions of ammonium salts. It is very susceptible to the action of water, which converts it into ammonia, zinc hydroxide and potassium hydroxide; even very short exposure to the action of the moisture of the air produces a superficial, sticky layer on the clean, dry crystals. It is not explosive. When heated in vacuo, potassium ammonozincate remains unaffected up to about $160^{\circ}$. As the temperature is increased the substance melts and gives off ammonia. One specimen heated to $250^{\circ}$ for some hours until the evolution of ammonia had practically ceased, gave off II.3 per cent. of ammonia and yielded a dark, vari- 
colored residue which gave on analysis 18.7 percent. nitrogen, 36.8 per cent. zinc and 44.7 per cent. potassium. Another specimen heated to $300^{\circ}$ for a considerable time lost I I.6 per cent. ammonia and gave a residue containing 18.8 per cent. nitrogen. The evolution of one and a half molecules of ammonia from $\mathrm{Zn}(\mathrm{NHK})_{2} \cdot 2 \mathrm{NH}_{3}$ would require a loss of I2.3 per cent. in weight, while a compound of the composition $\mathrm{Zn}(\mathrm{NHK})_{2} \cdot \mathrm{I} / 2 \mathrm{NH}_{3}$, would contain 19.2 per cent. nitrogen, 35.8 per cent. ziuc and $43 . \mathrm{I}$ per cent. potassium. As the temperature is raised ammonia mixed with permanent gases is given off and at the same time rings of metallic potassium and zinc are deposited in the cooler end of the tube. When a third specimen was heated to $325^{\circ}$ for many hours it lost 14.8 per cent. of its weight, apparently showing that even at this temperature all the ammonia of crystallization is not driven off. On emptying the tubes after heating these preparations to $250^{\circ}$ and higher, the glass walls of the tubes were found to be much attacked by the melted salt, a fact which accounts for the divergent analytical results and at the same time discouraged any further attempts to obtain a definite compound by the elimination of ammonia from the compound, $\mathrm{Zn}(\mathrm{NHK})_{2} \cdot 2 \mathrm{NH}_{3}$. In one experiment a tube lined with platinum was used in the hope that definite results might thus be obtained, but it was found that the melted salt also attacked this metal. It should be pointed out, however, that the results obtained point to the probable existence of a compound of the formula, $\mathrm{Zn}(\mathrm{NHK})_{2} \cdot 1 / 2 \mathrm{NH}_{3}$.

\section{Summary.}

It is shown by the work described above that a potassium ammonozincate, an ammonia analogue of the hypothetical water salt, potassium zincate, is obtained in the form of a definite, well crystallized compound by the action of a liquid ammonia solution of potassium amide, first, on metallic zinc, second, on zinc amide, and third, on zinc iodide, in accordance with the following respective equations:

$$
\begin{aligned}
& \text { I. } \mathrm{Zn}+2 \mathrm{KNH}_{2}+\mathrm{Am} .=\mathrm{Zn}(\mathrm{NHK})_{2} \cdot 2 \mathrm{NH}_{3}+\mathrm{H}_{2}, \\
& \text { 2. } \mathrm{Zn}\left(\mathrm{NH}_{2}\right)_{2}+2 \mathrm{KNH}_{2}=\mathrm{Zn}(\mathrm{NHK})_{2} \cdot 2 \mathrm{NH}_{3}, \\
& \text { 3. } \mathrm{ZnI}_{2} \cdot 4 \mathrm{NH}_{3}-4 \mathrm{KNH}_{2}=\mathrm{Zn}(\mathrm{NHK})_{2} \cdot 2 \mathrm{NH}_{3}+2 \mathrm{KI}+\mathrm{Am} .
\end{aligned}
$$

STANFORD CXIVERSITY,

Califoruia. June, 1907 .

[CONTRIBUTION FROM THE KENT CREMICAL LABORATORY OF THE UNIVERSITY OF CHICAGO.]

\section{THE ACTION OF HYDROCHLORIC ACID ON MANGANESE DIOXIDE.}

\section{(Preliminary Paper.)}

A great deal of work has been done upon the interaction of hydrochloric acid and manganese dioxide. Although the bulk of experimental 